\title{
Consumer acceptability of day care after operations for hernia or varicose veins
}

\author{
W. M. GARRAWAY, CONSTANCE CUTHBERTSON, NORMA FENWICK, \\ C. V. RUCKLEY, AND R. J. PRESCOTT
}

From the Departments of Community Medicine and Clinical Surgery and the Medical Computing and Statistics Unit, University of Edinburgh, and the General Surgical Unit, Western General Hospital, Edinburgh

SUMMARY The opinions of patients and of caring persons (usually relatives) were sought in this trial of different methods of providing care for 360 patients after operations for hernia or varicose veins. Analysis of patients' opinions suggested that day care was the most acceptable of the three types of care examined. The reactions of caring persons did not reveal any major criticisms or disadvantages.

Operations for hernia or varicose veins can be managed by day care surgery (Farquharson, 1955; Stephens and Dudley, 1961; Williams, 1969; Ruckley et al., 1973). In the absence of major differences in postoperative morbidity, the extent to which this method can be successfully implemented may largely depend on how acceptable it is to patients, their caring relatives, and their friends, as well as to members of the community health team who provide the aftercare. This paper presents the opinions of 360 patients and their caring relatives who took part in a trial of day care surgery which showed it to be safe.

\section{Methods}

Three types of care were compared. After operation for hernia or varicose veins, the patients were managed in (i) an acute hospital ward for two days (ii) a convalescent hospital for two days or (iii) at home in the care of a district nursing sister and a general practitioner under an established day care scheme. Allocation to treatment was made by a system of restricted randomisation.

The characteristics of the patients and further details of the methodology are given by Ruckley $e t$ al. (1978). All patients and caring persons were interviewed separately seven days after operation. The caring persons in the day care group were also interviewed 24 hours after operation.

\section{Results}

PATIENTS The characteristics of the patients (age, marital status, and social class) were similar in all treatment groups. Twenty-one per cent had previously experienced some form of day care or outpatient surgery, and $27 \%$ had already undergone at least one operation for varicose veins or hernia. These experiences did not appear to influence their answers to the questions.

\section{ADVANTAGES OF AFTERCARE \\ EXPRESSED BY PATIENTS}

Of those patients who considered that there were specific advantages of the aftercare they received, the highest proportion was in the day care group (Table 1). Four out of every five in this group who saw advantages for themselves in the scheme thought that the most beneficial aspect was being cared for in their own homes.

In the ward and convalescent groups, the advantage cited by patients was the fact that initial postoperative responsibility lay with the hospital and not with their caring persons. On the other hand, 13 out of 83 patients in the day care group who saw an advantage for their caring persons thought that the caring persons felt less domestic anxiety because the patients were at home.

Compared with those in the other groups, more than twice as many day care patients thought that there was a specific advantage for people other than their caring persons (other members of the family, for example) whom they saw during their aftercare. The day care group also emphasised the fact that there was less emotional distress among their families.

Eleven out of 360 patients made relevant comments about the implications for health service staff of the changing work load resulting from different forms of aftercare. 
Table 1 Percentages of patients expressing advantages and disadvantages of the three types of surgical aftercare

\begin{tabular}{|c|c|c|c|c|c|c|c|}
\hline & \multicolumn{4}{|c|}{ Types of aftercare } & \multicolumn{3}{|c|}{ Significance of differences } \\
\hline & $\begin{array}{l}\text { Ward } \\
n=121\end{array}$ & $\begin{array}{l}\text { Convalescent } \\
n=122\end{array}$ & $\begin{array}{l}\text { Daj } \\
n=\end{array}$ & 117 & $\begin{array}{l}\text { Ward vs } \\
\text { convalescent }\end{array}$ & $\begin{array}{l}\text { Ward vs } \\
\text { day care }\end{array}$ & $\begin{array}{l}\text { Convalescent vs } \\
\text { day care }\end{array}$ \\
\hline $\begin{array}{l}\text { ADVANTAGES SEEN BY PATIENTS } \\
\text { For themselves } \\
\text { For their caring persons } \\
\text { For others involved in aftercare }\end{array}$ & $\begin{array}{ll}\% & \text { No. } \\
79 & 95 \\
79 & 96 \\
13 & 16\end{array}$ & $\begin{array}{ll}\% & \text { No. } \\
71 & 87 \\
71 & 86 \\
12 & 15\end{array}$ & $\begin{array}{l}\% \\
92 \\
71 \\
29\end{array}$ & $\begin{array}{r}\text { No. } \\
108 \\
83 \\
34\end{array}$ & $\begin{array}{l}\text { NS } \\
\text { NS } \\
\text { NS }\end{array}$ & $\begin{array}{l}P<0.01 \\
N S \\
P<0.01\end{array}$ & $\begin{array}{l}\mathrm{P}<0.001 \\
\mathrm{NS} \\
\mathrm{P}<0.01\end{array}$ \\
\hline $\begin{array}{l}\text { DISADVANTAGES SEEN BY PATIENTS } \\
\text { For themselves } \\
\text { For their caring persons } \\
\text { For others involved in aftercare }\end{array}$ & $\begin{array}{rr}45 & 54 \\
12 & 14 \\
3 & 4\end{array}$ & $\begin{array}{rr}34 & 42 \\
30 & 37 \\
8 & 10\end{array}$ & $\begin{array}{r}20 \\
33 \\
8\end{array}$ & $\begin{array}{l}23 \\
39 \\
10\end{array}$ & $\begin{array}{l}\mathrm{NS} \\
\mathrm{P}<0.001 \\
\mathrm{NS}\end{array}$ & $\begin{array}{l}P<0.001 \\
P<0.001 \\
\text { NS }\end{array}$ & $\begin{array}{l}\mathrm{P}<0.05 \\
\text { NS } \\
\text { NS }\end{array}$ \\
\hline
\end{tabular}

DISADVANTAGES OF AFTERCARE EXPRESSED BY PATIENTS

Relatively fewer patients in the day care group mentioned any specific disadvantages for themselves, but they did see disadvantages for their caring persons (Table 1). They were concerned about possibly increased anxiety for the caring person, and about the additional domestic work. The inconvenience of hospital visiting was seen as the main disadvantage for the caring person in the other two groups. The overwhelming disadvantage for themselves mentioned by ward patients was the distress brought on by seeing the condition of surgical patients.

\section{CARING PERSONS}

POSTOPERATIVE ANXIETY Caring persons in the day care group were asked how they had coped during the 24 hours after operation. Thirty-two per cent said they had coped better than they had expected, $62 \%$ reported coping as well as expected, and only $2 \%$ said they had managed worse than expected. Four per cent expressed no opinion.

Just over $20 \%$ expressed apprehension about the remainder of the postoperative convalescence. No specific reasons could be elicited in most cases, but four caring persons were anxious about the postoperative condition of their patients and three were anxious to obtain more medical and/or nursing supervision for their patients. Twenty-one caring persons had coped with a specific problem such as vomiting, pain, or toileting, which had arisen during the first 24 hours in the home aftercare group.

\section{ADVANTAGES OF AFTERCARE}

EXPRESSED BY CARING PERSONS

Table 2 shows the proportion of caring persons who expressed a specific advantage for the surgical aftercare scheme in which they had participated.

The greatest advantage seen for patients in the day care group was being able to enjoy the facilities of their own homes. Caring persons who had patients in the ward group emphasised the advantages of 'the professional care that could not be provided at home'. This response was less marked among caring persons with patients in the convalescent group. Relief from early postoperative responsibility was also emphasised by the two hospital groups of caring persons. Other advantages mentioned included 'no disruption of employment'; 'less work'; or 'easier to manage at home'.

\section{DISADVANTAGES OF AFTERCARE}

EXPRESSED BY CARING PERSONS

A relatively low proportion of caring persons in each of the three groups was able to think of

Table 2 Percentages of caring persons expressing specific advantages and disadvantages of the three types of surgical aftercare

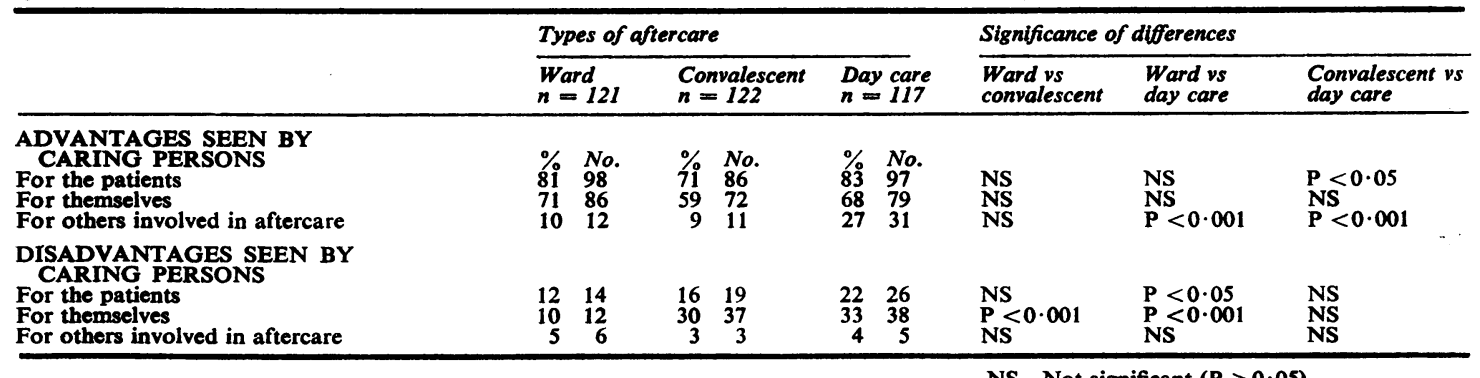


specific disadvantages of the scheme they had experienced. The highest proportion of disadvantages was mentioned by those in the day care group (Table 2). However, only 12 out of 38 caring persons in this group who expressed a disadvantage considered initial postoperative responsibility to be the major disadvantage for themselves.

Six caring persons in the day care group commented that their patients should have had a longer stay in hospital but eight caring persons in the two hospital groups thought that their patients should have been allowed home sooner. Only three caring persons in the day care group thought that the increased work load for the general practitioner and district nursing sister was a major disadvantage of the scheme.

\section{LONGER HOSPITAL STAY}

Patients and caring persons were asked independently whether they would have preferred a longer period of hospital care. Only $9 \%$ of patients and $17 \%$ of caring persons said 'Yes', and the proportions were similar in all groups. The total amount of extra time in hospital preferred by patients was 23 days in the ward group, 42 days in the convalescent group, and 22 days in the day care group. The corresponding figures given by caring persons were 49 days, 100 days, and 55 days.

\section{Discussion}

In any comparative assessment of different methods of care, attempts to gauge acceptability to the public are usually beset by one major limitation which is difficult to overcome. Subjects in controlled trials are allowed one or other of several options. They can only describe their subjective reactions to their particular situation, and without a crossover design, they have no other experience to provide a comparison. In this study, we have assumed that participants in each group had little or no insight into how they would have reacted to either of the other allocations.
The data indicate that patients in the day care group made a more favourable response than those in the ward or convalescent groups. A higher proportion could name more specific advantages and fewer specific disadvantages than in either of the other two groups. Although they were discharged at a mean time of only four and a half hours after the operation, only one patient in every 10 and one caring person in every five in the day care group expressed a preference for a longer hospital stay, figures mirrored in the other two groups. Patients in the day care group appeared to have a reasonable insight into the responsibility and additional work which their caring persons had to shoulder. One quarter of such patients expressed this as a disadvantage for their caring persons. This might be seen as the only barrier to the acceptability of day care surgery, except that this disadvantage is not sustained among the caring persons themselves. Only $10 \%$ of caring persons in the day care group considered the postoperative responsibility a disadvantage of the scheme.

Reprints from W. M. Garraway, Department of Community Medicine, Usher Institute, Warrender Park Road, Edinburgh EH9 1DW.

\section{References}

Farquharson, E. L. (1955). Early ambulation with special reference to herniorrhaphy as an outpatient procedure. Lancet, 2, 517-519.

Ruckley, C. V., Ludgate, C. M., Maclean, M., and Espley, A. J. (1973). Major outpatient surgery, Lancet, 2, 1193-1196.

Ruckley, C. V., Cuthbertson, C. J. C., Fenwick, N., Garraway, W. M., and Prescott, R. J. (1978). Day care after operations for hernia or varicose veins-a controlled trial. British Journal of Surgery, 65, 456-459.

Stephens, F. O., and Dudley, H. A. F. (1961). An organisation for outpatient surgery. Lancet, 1, 1042-1044.

Williams, J. A. (1969). Outpatient operations. I-The surgeon's view. British Medical Journal, 1, 174-175. 